\title{
Atypical bilateral ventilation/perfusion mismatches in an asymptomatic patient suffering from metastatic thyroid cancer
}

\author{
David Kersting ${ }^{1,4^{*}}$ (D) Christoph Rischpler ${ }^{1,4}$, Till Plönes ${ }^{2}$, Clemens Aigner ${ }^{2}$, Lale Umutlu ${ }^{3,4}$, Ken Herrmann ${ }^{1,4}$ and \\ Hubertus Hautzel ${ }^{1,4}$
}

\author{
*Correspondence: \\ david.kersting@uni-due.de \\ 1 Department of Nuclear \\ Medicine, University \\ Hospital Essen, West German \\ Cancer Center (WTZ), \\ University of Duisburg- \\ Essen, Hufelandstrasse 55, \\ 45147 Essen, Germany \\ Full list of author information \\ is available at the end of the \\ article
}

\begin{abstract}
Background: Pulmonary embolism is indicated by ventilation/perfusion (V/P) mismatches in ventilation/perfusion scintigraphy. However, other pathologies may also evoke segmental or lobar mismatches. Thus, diagnosis can be difficult in asymptomatic patients with equivocal clinical presentation.

Case presentation: We present a case of multiple bilateral pulmonary ventilation/ perfusion mismatches in a poorly differentiated thyroid cancer patient. Exact diagnosis was difficult, as the patient was asymptomatic and pulmonary embolism is commonly unilateral in tumour patients and not typical for thyroid cancer. External pulmonary artery compression by aortic aneurysm, multiple metastases or additional bronchopulmonary malignancies were considered as differential diagnosis. After unilateral pulmonary and hilar metastasectomy, perfusion normalised on the operated side. Pulmonary perfusion defects due to pulmonary artery compression by hilar metastases were finally diagnosed. Pulmonary embolism was deemed unlikely due to the left-sided post-operative normalisation, persistence of right-sided V/P mismatches, and the lack of clinical symptoms.

Conclusion: Pulmonary artery compression may mimic pulmonary artery embolism in lung perfusion scintigraphy and should be considered in bronchopulmonary tumour patients with hilar metastases and unilateral ventilation/perfusion mismatches affecting a complete lobe or even lung. Following the presented case, also bilateral segmental and subsegmental mismatches in patients with hilar metastases from nonbronchopulmonary cancer entities should be carefully evaluated.
\end{abstract}

Keywords: Perfusion scintigraphy, MAA SPECT, Pulmonary embolism, Thyroid cancer

\section{Background}

Segmental or subsegmental ventilation/perfusion (V/P) mismatches in ventilation/perfusion scintigraphy indicate pulmonary embolism $(\mathrm{PE})$ with high sensitivity and specificity (Bajc et al. 2019). However, other pathologies such as vasculitis or congenital vascular abnormalities may also evoke segmental or lobar mismatches (Bajc et al. 2019). Thus, diagnosis can be difficult in cases with equivocal clinical presentation.

(9) The Author(s), 2021. Open Access This article is licensed under a Creative Commons Attribution 4.0 International License, which permits use, sharing, adaptation, distribution and reproduction in any medium or format, as long as you give appropriate credit to the original author(s) and the source, provide a link to the Creative Commons licence, and indicate if changes were made. The images or other third party material in this article are included in the article's Creative Commons licence, unless indicated otherwise in a credit line to the material. If material is not included in the article's Creative Commons licence and your intended use is not permitted by statutory regulation or exceeds the permitted use, you will need to obtain permission directly from the copyright holder. To view a copy of this licence, visit http:// creativecommons.org/licenses/by/4.0/. 
PE due to venous thromboembolism (VTE), mostly diagnosed in routine staging CT, is a frequent and challenging complication in cancer patients (Donadini et al. 2014). However, in thyroid cancer patients only little data are available on VTE, which may be unlikely in this patient cohort (Ordookhani et al. 2018). Differential diagnoses are perfusion defects due to external compression by aortic aneurysm (Makis and Derbekyan 2012), metastases, or bronchopulmonary tumours (Cei et al. 2004). Additionally, vasculitis and congenital pulmonary vascular malformations (Bajc et al. 2019), pulmonary arterial hypertension (Chan et al. 2018), and extensive emphysematic bullae (Reinartz et al. 2004) can be considered. Recently, a unilateral perfusion defect caused by pulmonary vein stenosis after pulmonary vein isolation has been reported (Kind et al. 2021).

\section{Case presentation}

A 38-year-old man was referred to our clinic 6 months after initial diagnosis of poorly differentiated thyroid carcinoma (TNM: pT3a pN1b pM1). Prior to resection of radioiodine-negative pulmonary metastases, perfusion scintigraphy was requested for preoperative risk evaluation, as sequential bilateral metastasectomy was planned. In addition, the patient showed a reduced lung reserve in pulmonary function testing (maximum vital capacity $3.9 \mathrm{~L}, 80 \%$ of the nominal value; forced vital capacity $3.5 \mathrm{~L}, 69 \%$ of the nominal value; forced expiratory volume in $1 \mathrm{~s} 2.9 \mathrm{~L}, 71 \%$ of the nominal value). Thoracic SPECT imaging after application of ${ }^{99 \mathrm{~m}} \mathrm{Tc}$-macro-aggregated albumin (MAA) demonstrated multiple bilateral pulmonary (multi-)segmental (right lower lobe, middle lobe, left upper lobe) and subsegmental (e.g., right upper lobe) perfusion defects (Fig. 1A-C). Subsequently performed ventilation SPECT using ${ }^{99 \mathrm{~m}} \mathrm{Tc}$-Technegas did not show any impairment (Fig. 1D-F). The V/P mismatches were highly suspicious of multifocal PE. However, the patient did not report symptoms of PE. Both blood panel and spirometry did not reveal any pathological findings; oxygen saturation was $98.5 \%$. The clinical pretest probability for PE was low with a Wells score of 1 and a revised Geneva score of 2. In combination with the clinical findings, PE was deemed unlikely; therefore, no anticoagulation treatment was initiated. The planned resection was extended to left pulmonary and left hilar metastasectomy: 8 pulmonary wedges containing metastases (S3, S4, upper lobe/lingula, S10, lower lobe/diaphragm surface) and an aortopulmonary window lymph node metastasis were resected. Another hilar metastasis was not removed because of its close proximity to the upper lobe artery. As subsequent right-sided metastasectomy was considered, a follow-up perfusion SPECT was performed 2 weeks after left-sided metastasectomy. Left-sided pulmonary perfusion was normalised apart from one newly occurring subsegmental defect in left inferior lobe segment S10 (Fig. 1H) interpreted as post-surgical (compare Fig. $1 \mathrm{~B}$ and $\mathrm{H}$ ), while perfusion defects on the right side that had not underwent surgery remained unaltered (Fig. 1G-I). Within 1 week after the second perfusion SPECT, 4 pulmonary wedges containing metastases (upper lobe, lower lobe fissure, S6, S10) were resected on the right side. Mediastinal metastases were not resected since they were in close proximity to central vessels and bronchi.

A CT pulmonary angiogram directly after the initial V/P SPECT but preceding both metastasectomies revealed bilateral pulmonary artery compression due to bihilar metastases (Fig. 2B); however, also contrast media filling defects in segmental arteries were reported (Fig. 2A). In a follow-up ${ }^{18} \mathrm{~F}$-FDG PET/MRI 2 months later, right hilar 

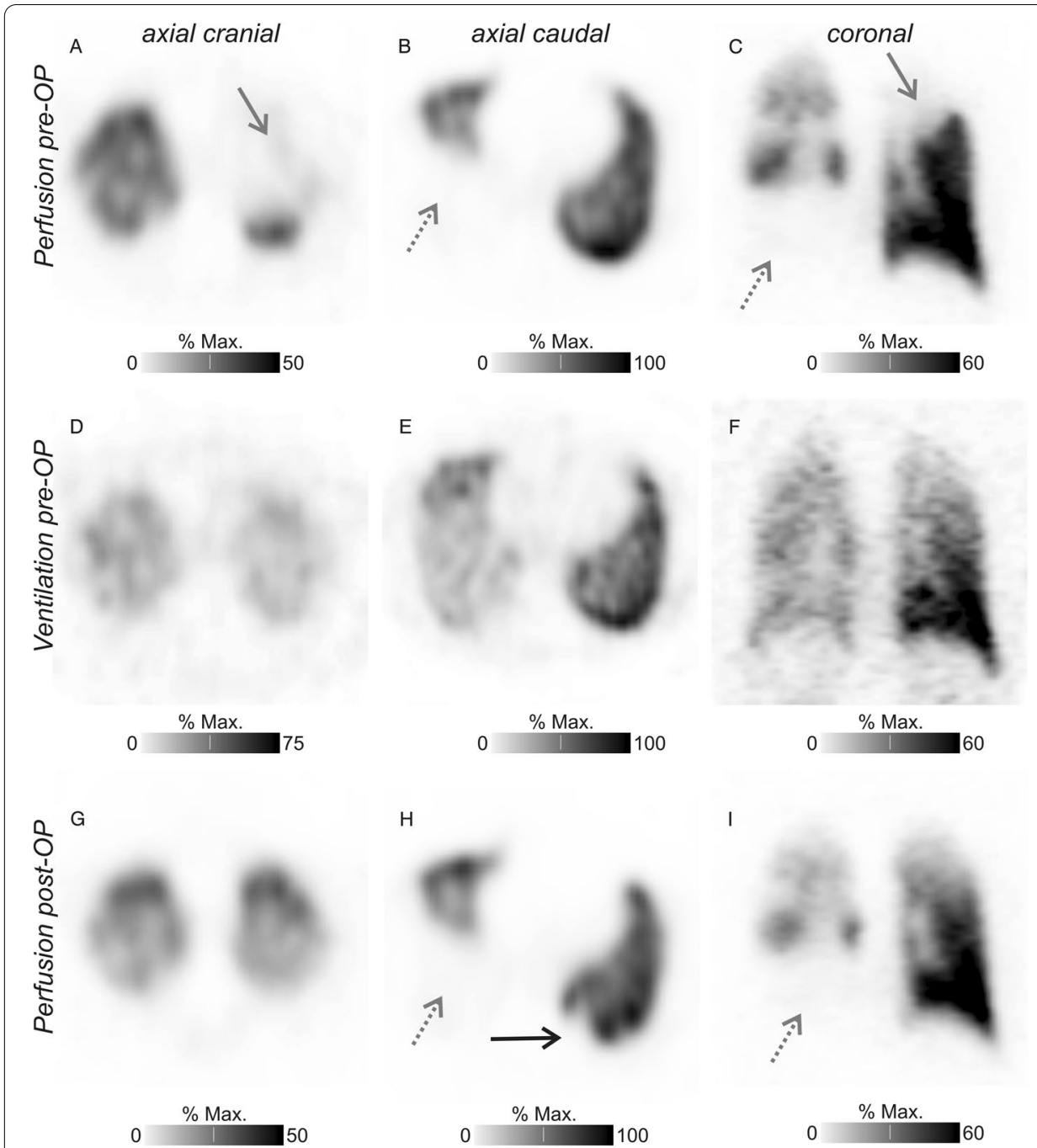

Fig. 1 Preoperative perfusion $(\mathbf{A}-\mathbf{C})$, corresponding preoperative ventilation (D-F) and post-operative follow-up (G-I) perfusion SPECT images. Perfusion defects are indicated by solid (left superior lobe segments $\mathrm{S} 1 / 2 \mathrm{~L}$ and $\mathrm{S} 3 \mathrm{~L}$ ) and dashed grey arrows (middle lobe and right inferior lobe). Left-sided pulmonary perfusion was normalised after surgery; a subsegmental probably post-surgical defect is indicated by a black arrow (left inferior lobe segment S10L)

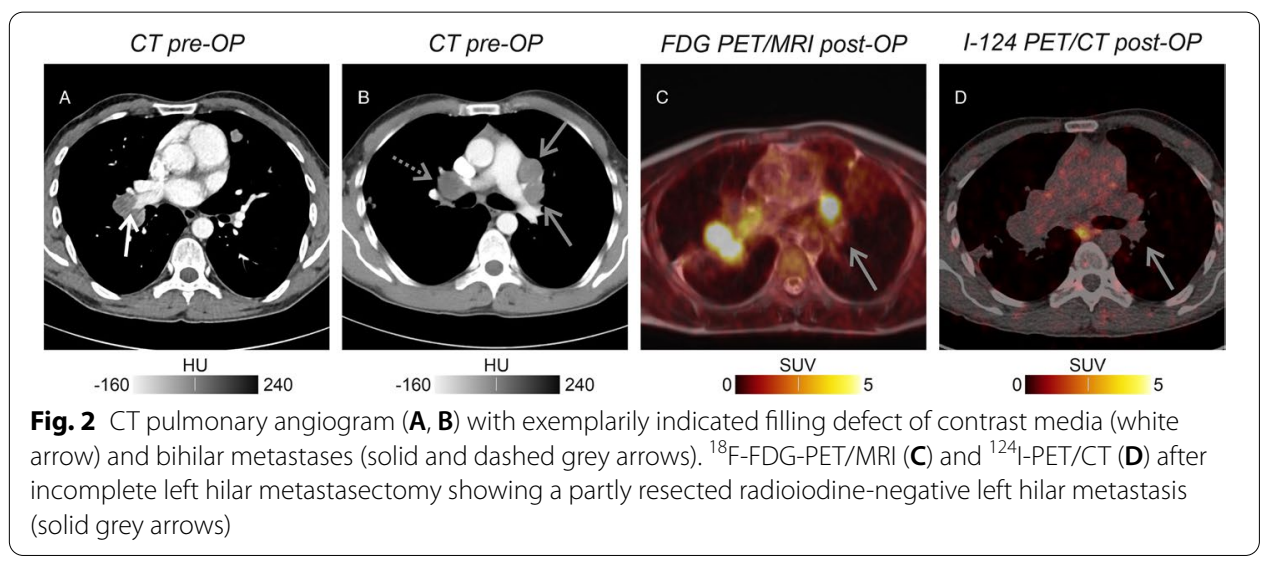


metastases were still visualised with intense glucose uptake, whereas left hilar metastases were partly resected (Fig. 2C). As these metastases did not show radioiodine uptake in ${ }^{124}$ I PET/CT (Fig. 2D), systemic tyrosine kinase inhibitor treatment was started. Pulmonary perfusion defects due to pulmonary artery compression by hilar metastases were finally diagnosed. Pulmonary embolism was deemed unlikely due to the left-sided post-operative normalisation, persistence of right-sided V/P mismatches and the lack of clinical symptoms.

\section{Conclusions}

Pulmonary artery compression may mimic pulmonary artery embolism in lung ventilation/perfusion scintigraphy and should be considered in tumour patients with hilar metastases. Ventilation/perfusion mismatches are reported for bronchopulmonary cancer; these are rare pitfalls in lung scintigraphy but commonly unilaterally affect a complete lobe or lung. Following the presented case, also bilateral lobar, segmental and subsegmental mismatches in patients with hilar metastases from non-bronchopulmonary cancer entities should be carefully evaluated.

\section{Abbreviations \\ MAA: ${ }^{99 M}$ Tc-macro-aggregated albumin; PE: Pulmonary embolism; V/P: Ventilation/perfusion; VTE: Venous thromboembolism.}

Acknowledgements

None.

Authors' contributions

DK and $\mathrm{HH}$ analysed the case, co-wrote the manuscript and approved its final content. CR, TP, CA, LU and KH critically revised the manuscript and approved its final content. All authors read and approved the final manuscript.

\section{Funding}

Open Access funding enabled and organized by Projekt DEAL. This work was supported by the Universitätsmedizin Essen Clinician Scientist Academy (UMEA)/German Research Foundation (DFG, Deutsche Forschungsgemeinschaft) under Grant FU356/12-1 to DK.

Availability of data and materials

The data sets generated and/or analysed during the current study are not publicly available due to privacy legislation but are available from the corresponding author on reasonable request.

\section{Declarations}

Ethics approval and consent to participate

The local ethics committee (Ethics committee, University Duisburg-Essen, faculty of medicine) waived the need for approval.

\section{Consent for publication}

Written informed consent was obtained from the patient for publication of this case report and accompanying images.

\section{Competing interests}

No potential conflict of interest relevant to this article was reported. Christoph Rischpler reports research grants from Pfizer, outside of the submitted work. Lale Umutlu is a Speaker/Advisory Board Member for Bayer Healthcare and Siemens Healthcare and received research grants from Siemens Healthcare, outside of the submitted work. Ken Herrmann reports personal fees from Bayer, personal fees and other from Sofie Biosciences, personal fees from SIRTEX, non-financial support from ABX, personal fees from Adacap, personal fees from Curium, personal fees from Endocyte, grants and personal fees from BTG, personal fees from IPSEN, personal fees from Siemens Healthineers, personal fees from GE Healthcare, personal fees from Amgen, personal fees from Novartis and personal fees from ymabs, outside of the submitted work.

\section{Author details}

${ }^{1}$ Department of Nuclear Medicine, University Hospital Essen, West German Cancer Center (WTZ), University of DuisburgEssen, Hufelandstrasse 55, 45147 Essen, Germany. ${ }^{2}$ Department of Thoracic Surgery and Thoracic Endoscopy, University Medicine Essen - Ruhrlandklinik, West German Cancer Center (WTZ), University of Duisburg-Essen, Essen, Germany.

${ }^{3}$ Department of Diagnostic and Interventional Radiology and Neuroradiology, University Hospital Essen, West German 
Cancer Center (WTZ), University of Duisburg-Essen, Essen, Germany. ${ }^{4}$ German Cancer Consortium (DKTK), Partner Site University Hospital Essen, Essen, Germany.

Received: 30 September 2021 Accepted: 15 November 2021

Published online: 20 December 2021

\section{References}

Bajc M, Schumichen C, Gruning T, Lindqvist A, Le Roux PY, Alatri A et al (2019) EANM guideline for ventilation/perfusion single-photon emission computed tomography (SPECT) for diagnosis of pulmonary embolism and beyond. Eur J Nucl Med Mol Imaging 46(12):2429-2451. https://doi.org/10.1007/s00259-019-04450-0

Cei M, Mumoli N, Mariotti F, Pardelli R (2004) The importance of clinical suspicion in diagnosing pulmonary embolism: a case of false-positive high probability radionuclide perfusion lung scan. Eur J Emerg Med 11(4):234-236. https://doi. org/10.1097/01.mej.0000134839.34865.1f

Chan K, loannidis S, Coghlan JG, Hall M, Schreiber BE (2018) Pulmonary arterial hypertension with abnormal V/Q singlephoton emission computed tomography. JACC Cardiovasc Imaging 11(10):1487-1493. https://doi.org/10.1016/j. jcmg.2017.07.026

Donadini MP, Dentali F, Squizzato A, Guasti L, Ageno W (2014) Unsuspected pulmonary embolism in cancer patients: a narrative review with pooled data. Intern Emerg Med 9(4):375-384. https://doi.org/10.1007/s11739-014-1066-7

Kind F, Goetz C, Meyer PT, Foll D, Russe MF, Ruf J (2021) Pulmonary vein stenosis as a pitfall of ventilation/perfusion SPECT/CT for pulmonary embolism. Clin Nucl Med 46(3):238-239. https://doi.org/10.1097/RLU.0000000000003462

Makis W, Derbekyan V (2012) Compression of the right pulmonary artery by a massive descending aortic aneurysm causing bilateral perfusion defects on pulmonary scintigraphy. Nucl Med Mol Imaging 46(1):65-68. https://doi.org/10. 1007/s13139-011-0098-4

Ordookhani A, Motazedi A, Burman KD (2018) Thrombosis in thyroid cancer. Int J Endocrinol Metab 16(1):e57897. https:// doi.org/10.5812/ijem.57897

Reinartz P, Wildberger JE, Schaefer W, Nowak B, Mahnken AH, Buell U (2004) Tomographic imaging in the diagnosis of pulmonary embolism: a comparison between V/Q lung scintigraphy in SPECT technique and multislice spiral CT. J Nucl Med 45(9):1501-1508

\section{Publisher's Note}

Springer Nature remains neutral with regard to jurisdictional claims in published maps and institutional affiliations.

\section{Submit your manuscript to a SpringerOpen ${ }^{\circ}$ journal and benefit from:}

- Convenient online submission

Rigorous peer review

- Open access: articles freely available online

- High visibility within the field

- Retaining the copyright to your article

Submit your next manuscript at $\gg$ springeropen.com 